\title{
A cut-off of daily sedentary time and all-cause mortality in adults: a meta- regression analysis involving more than 1 million participants
}

\author{
Po-Wen Ku' ${ }^{1}$ Andrew Steptoe ${ }^{2}$, Yung Liao ${ }^{3}$, Ming-Chun Hsueh ${ }^{4 *}$ and Li-Jung Chen ${ }^{5^{*}}$
}

\begin{abstract}
Background: The appropriate limit to the amount of daily sedentary time (ST) required to minimize mortality is uncertain. This meta-analysis aimed to quantify the dose-response association between daily ST and all-cause mortality and to explore the cut-off point above which health is impaired in adults aged 18-64 years old. We also examined whether there are differences between studies using self-report ST and those with device-based ST.

Methods: Prospective cohort studies providing effect estimates of daily ST (exposure) on all-cause mortality (outcome) were identified via MEDLINE, PubMed, Scopus, Web of Science, and Google Scholar databases until January 2018. Dose-response relationships between daily ST and all-cause mortality were examined using random-effects meta-regression models.

Results: Based on the pooled data for more than 1 million participants from 19 studies, the results showed a log-linear dose-response association between daily ST and all-cause mortality. Overall, more time spent in sedentary behaviors is associated with increased mortality risks. However, the method of measuring ST moderated the association between daily ST and mortality risk $(p<0.05)$. The cut-off of daily ST in studies with self-report ST was $7 \mathrm{~h} /$ day in comparison with $9 \mathrm{~h} /$ day for those with device-based ST.

Conclusions: Higher amounts of daily ST are log-linearly associated with increased risk of all-cause mortality in adults. On the basis of a limited number of studies using device-based measures, the findings suggest that it may be appropriate to encourage adults to engage in less sedentary behaviors, with fewer than $9 \mathrm{~h}$ a day being relevant for all-cause mortality.
\end{abstract}

Keywords: Sedentary behavior, Sitting, Inactivity, Review, Cut-point, Recommendation

\section{Background}

A sedentary lifestyle is prevalent among adults in the present era. A recent multi-country study based on 12 sites in 10 countries including the USA, Brazil, the UK, Denmark, the Czech Republic, and China (Hong Kong) of adults aged 18-66 using accelerometry found that the average sedentary time (ST) per day was $8.65 \mathrm{~h}$ (standard

\footnotetext{
* Correspondence: boxeo@ntnu.edu.tw; ljchen@gm.ntupes.edu.tw ${ }^{4}$ Department of Physical Education, National Taiwan Normal University, NO.162, He-ping East Road, Section 1, Taipei 106, Taiwan

${ }^{5}$ Department of Exercise Health Science, National Taiwan University of Sport, No. 16, Section 1, Shuang-Shih Rd., Taichung 404, Taiwan

Full list of author information is available at the end of the article
}

deviation $[\mathrm{SD}]=1.8)[1]$. ST was estimated to be responsible for $3.8 \%$ of all-cause mortality in adults according to a meta-analysis pooling data across 54 countries [2]. Prolonged ST has been increasingly recognized as a serious issue in public health [3], and recommendations have begun to appear in public health guidelines [4], suggesting that all adults should minimize the amount of ST $[5,6]$. To conduct screening and surveillance of the health hazards of a sedentary lifestyle and develop feasible intervention strategies and evidence-based recommendations, it is crucial to identify a cut-off or limit on the amount of ST per day, above which health is impaired.

(c) The Author(s). 2018 Open Access This article is distributed under the terms of the Creative Commons Attribution 4.0 International License (http://creativecommons.org/licenses/by/4.0/), which permits unrestricted use, distribution, and reproduction in any medium, provided you give appropriate credit to the original author(s) and the source, provide a link to the Creative Commons license, and indicate if changes were made. The Creative Commons Public Domain Dedication waiver (http://creativecommons.org/publicdomain/zero/1.0/) applies to the data made available in this article, unless otherwise stated. 
The Australian government has proposed that that the cut-off point for risk is approximately 7 or $8 \mathrm{~h}$ a day [7], but the current evidence is inconsistent. Based on six studies (five using self-reported measures vs. one using a device-based measure), a meta-analysis examining the relationships between daily ST and all-cause mortality revealed that more than $7 \mathrm{~h}$ per day is associated with increased mortality risk [8]. In contrast, another recent meta-analysis based on 13 studies (all based on selfreported measures) found an increased risk of all-cause mortality among adults spending 4 or more hours per day in sedentary behaviors [9], which could be attenuated by the levels of moderate-to-vigorous physical activity (MVPA) as a moderator. Although the evident discrepancy may be due to heterogeneity across studies, one of the major limitations is that almost all the studies included in these two meta-analyses were based on selfreport ST. Compared with devices, subjective measures such as questionnaires tend to be less accurate due to recall bias $[10,11]$. Currently, there is insufficient evidence on which to provide specific public health recommendations regarding the appropriate limit to the amount of daily ST required to minimize mortality, especially using device-based assessments.

To address these shortfalls, our study involved metaregression analyses to quantify the dose-response association between daily ST and all-cause mortality in adults aged 18-64 years old and to explore the cut-off duration associated with elevating the risk of all-cause mortality through reviewing evidence based on subjective measurements and recent studies using device-based ST [12-15]. We also examined whether there are distinct differences between studies involving self-report ST and those using device-based measures of ST.

\section{Methods}

\section{Search strategy and selection criteria}

Five databases, MEDLINE, PubMed, Scopus, Web of Science, and Google Scholar, were searched up to January 31, 2018 to identify potential studies examining relationships of sedentary behaviors with all-cause mortality in adults (aged 18-64 years). The following search strings were used: (("sitting time" OR "sedentary behavior" OR "sedentary behavior") AND (mortality OR mortalities OR death OR fatal)) AND (risk OR Cox OR hazard OR survival analysis OR odds). Additional studies were identified by manually checking the reference lists of included papers.

Article eligibility for inclusion was based on the following criteria: (1) original articles published in English before January 31, 2018; (2) articles involving a prospective cohort design; (3) involvement of participants in the age range of 18 to 64 years or the mean age in this range at baseline; (4) daily total ST or overall sitting time used as an exposure variable and all-cause mortality as an outcome variable; and (5) reported effect estimates of relative risk (RR) or odds ratios (ORs) or hazard ratios (HRs) with 95\% confidence intervals (CIs) for all-cause mortality.

The exclusion criteria were applied to articles that: (1) focused on clinical populations such as patients with cardiovascular diseases, type 2 diabetes, or cancer etc.; (2) did not provide cut-off durations of total sedentary or sitting time; or (3) did not adjust for physical activity, since physical activity may be a confounding factor for the relationships of death with prolonged ST $[12,13]$.

\section{Data extraction and quality assessment}

The following data were extracted from the retrieved articles: author(s), year of publication, country, study population (sample size/death, age at baseline, and gender), follow-up time, total ST measure, covariates that were adjusted for in the analysis, and the HR estimates with corresponding 95\% CIs for the models. Two authors independently extracted the data from each study and compared them for consistency. Any discrepancies between the two reviewers were settled through discussion, and a third reviewer's help was sought for resolving disagreements.

The study appraisal criteria and characteristics for each study are presented in Additional file 1: Table S1. Using the study quality checklist proposed by Kmet, Lee, and Cook [16], two authors (MH and YL) independently assessed the studies, and any disagreements were resolved by consensus. Studies were scored ( 0 for no, 1 for partial, 2 for yes) on 14 criteria by the following questions: Question/objective sufficiently described? and Study design evident and appropriate? [16], and the score of each study is presented in Additional file 2: Table S2. The sum of all scores was then divided by the highest possible score, giving quality scores ranging from 0 (worst) to 1 (best). A score $\geq 0.85$ was defined as being of high quality [9].

\section{Statistical analysis}

Categorization of ST was based on the data available from each study. The maximally adjusted HR estimates from multivariable proportional hazards models were utilized to reduce the confounding effect in each study. To identify the cut-off of ST duration for increasing the risk of all-cause mortality, "dose of ST" was assigned, using the median or mean level of ST in each category, to the corresponding relative risk for each study. When ST was reported by ranges of time, the midpoint of the range was estimated. When the highest category was open ended, the length of the open-ended interval was assumed to be the same as that of the adjacent interval. 
When the lowest category was open ended, the lower boundary was set to zero $[17,18]$. Measures of association (HRs) and the corresponding CIs were transformed into the natural logarithm of the HRs and their variances. The statistical heterogeneity among studies was evaluated using $I^{2}$ (i.e., the proportion of total variation contributed by between-study variance) [19].

To assess the shape of the associations of ST with log-transformed risk of all-cause mortality using pooled data extracted from the 19 prospective cohort studies, random-effects meta-regression models were used. Linear, quadratic, and cubic models were fitted to determine the model of best fit for the pooled doseresponse data first [20]. Additionally, to explore a range of possible functions such as U-shaped and J-shaped patterns, second-order fractional polynomial models, including the quadratic model, were also comprehensively evaluated: $(\log H R \mid X)=\beta_{1} X^{\mathrm{P} 1}+\beta_{2} X^{\mathrm{P} 2}$. In this equation, $\mathrm{P} 1$ and $\mathrm{P} 2$ were chosen from a predefined set $\mathrm{P}=[-2,-1,-0.5,0,0.5,1,2]$ [21]. The results of goodness-of-fit tests among these models (including the linear model, the second-order fractional polynomial models, and the cubic model) are shown in Additional file 3: Table S3. The model selection was based on two criteria: (1) more variance between studies were explained by the model (i.e., $R^{2}$ analog) [22]; (2) the coefficients of each regression model were significantly different from zero. Among them, the linear model was chosen. Therefore, a random-effects meta-regression model based on linear dose-response relationships with restricted maximum likelihood estimations was utilized in the following analyses. To estimate the dispersion across studies and provide more accurate estimates, the KnappHartung method was applied in the random-effects metaregression analyses; this method additionally uses a refined estimator of between-studies variance of the effect estimator via a Student's $t$ distribution instead of a $Z$ distribution $[23,24]$. This method has the effect of expanding the width of the CIs and yields a more conservative inference.

Several random-effects meta-regression models were used as follows. First, the linear dose-response relationship between ST and all-cause mortality was examined based on all studies (Model 1). Second, the independent effects of ST and measurement of ST (device-based [1] vs. subjective [0]) on the heterogeneity of mortality risks were assessed in Model 2. Third, to assess whether measurement of ST moderates the association of ST with subsequent mortality risks across studies, Model 2 was rerun by further including an interaction term $(\mathrm{ST} \times$ measurement of ST). Finally, given the statistically significant interaction effect $(p<0.05)$, two separate meta-regression models were conducted for studies using subjective measures and those with device-based instruments (Models 3 and 4).
Sensitivity analyses were performed to address potential confounding effects. The study-level variables, which may account for the heterogeneity of mortality risks, were scrutinized in a simple meta-regression model. In addition to measurement of ST (subjective vs. devicebased), gender, mean age, year of publication, and mean length of follow-up were assessed. Among them, only mean length of follow-up reached significance $(p<0.05)$. Because of potential confounding due to the differences in length of study follow-up, the time for follow-up was further included in Model 2 (Model 5). Model 5 was also repeated by further including in it an interaction term (ST $\times$ measurement of ST).

To visualize the association of ST and mortality risk and identify the potential cut-off of ST, scatter plots with regression lines and 95\% CIs (Model 2: total studies, Model 3: studies with self-reported ST, and Model 4: studies with device-based ST) were obtained using meta-regression models. The follow-up time of each study as a continuous variable was further included in the three models for adjustment.

Publication bias was evaluated by a visual investigation of funnel plots for potential asymmetry and assessed with Egger's test [25] and Duval and Tweedie's "trim and fill" test [26].

All analyses were performed with Comprehensive Meta-Analysis Version 3.3.070 (Biostat, Englewood, NJ, USA) [22]. All $p$ values were two-sided and were considered significant at $p<0.05$.

\section{Results}

\section{Study characteristics}

A total of 254 articles were identified through five different database searches $(n=238)$ and reference list searches $(n=16)$ (see the Preferred Reporting Items for Systematic Reviews and Meta-Analyses [PRISMA] flowchart in Fig. 1) [27]. Subsequently, after duplicates were removed, a total of 240 articles were retrieved to endnote. When the abstracts were screened, a total of 28 full-text articles were obtained for further review. We removed 9 of these based on the following exclusion criteria after contacting the authors of the original studies when missing information was not available in their articles: (1) mean age of the study population was $\geq 65$ $(n=4)$ [28-31]; (2) the study sample was based on participants in clinical trials on hormone therapy $(n=1)$ [32]; (3) the cut-off point of the total sitting time was not provided $(n=2)[33,34]$; (4) there was no adjustment for physical activity in the multivariable model $(n=1)$ [35]; (5) devices were used to estimate ST without excluding sleep time $(n=1)$ [36]. Finally, 19 studies were included for meta-analysis, and the quality scores were high in all studies (average $=0.96 ; \geq 0.85$ was defined as high quality) [9] (see Additional file 2: Table S2). 


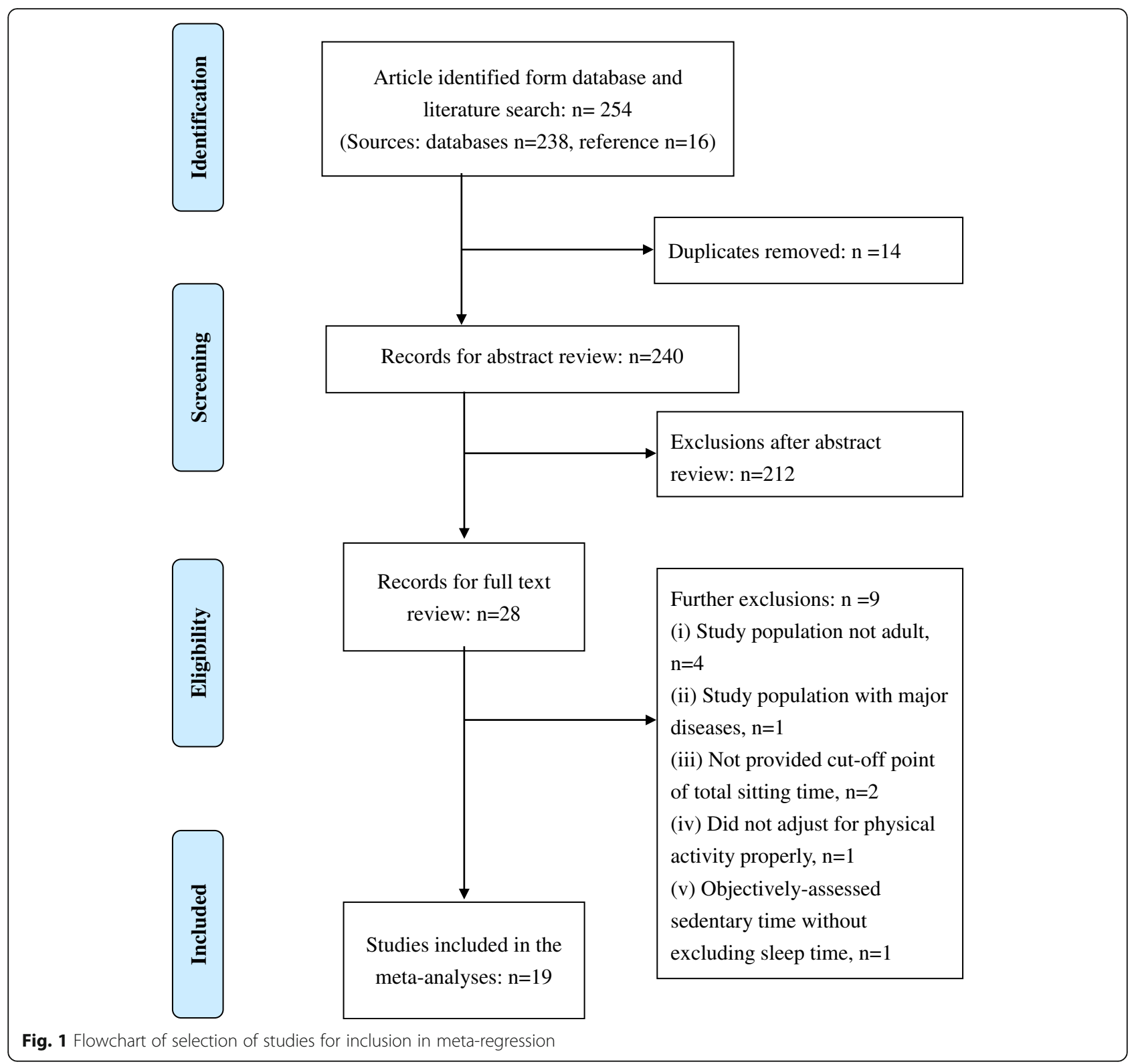

Data from all studies were extracted and are summarized in Additional file 1: Table S1. The 19 studies in the meta-analysis included 1,259,482 individuals who were followed up for 2.8-15.7 (mean time $=7.8$ ) years, among whom 86,671 (6.9\%) died [12-15, 37-47]. The mean age of participants in these studies ranged from 39.7 to 63.8 years old. Twelve studies assessed data by self-report ST [37-48] in comparison with seven studies with device-based ST $[12-15,49-51]$. The measures of self-report ST among the 12 studies were brief. Seven studies utilized a single item [37-40, 42, $47,48]$, three studies used two items [41, 45, 46], one used three items [44], and another one used five items [43]. The cut-off points for the categories were not consistent across the studies (see Additional file 1: Table S1). All studies adjusted for multiple potential confounding factors including at least gender, age, and physical activity, while 16 out of 19 studies also adjusted for education and smoking, 14 studies for body mass index (BMI), and 12 studies for alcohol consumption. Other covariates used for adjustment in the studies in this meta-analysis comprised race, marital status, urbanization, occupation, income, and comorbidity (see Additional file 1: Table S1).

The heterogeneity of effect estimates among studies based on $I^{2}$ was $85.64 \%$, suggesting a relatively high inconsistency across the findings in the included studies [52]. 


\section{Sedentary time and mortality: dose-response meta-regression}

The meta-regression based on all included studies indicated a linear dose-response relationship between daily ST and log-transformed risk of all-cause mortality (Model 1 in Table 1). The Model 2 analyses demonstrated that both daily ST and measurement of ST (device-based vs. subjective) independently account for the heterogeneity in mortality risks. Model 2 was rerun after further inclusion of an interaction term, revealing a statistically significant interaction effect $(p=0.02)$.

Two separate meta-regression models were then conducted for studies using subjective measures and those with device-based instruments (Models 3 and 4). ST was significantly associated with all-cause mortality in both models. However, the magnitude of associations was stronger in studies using devices (regression coefficient $=0.09$ ) than in those based on subjective instruments (regression coefficient $=0.03$ ).

In sensitivity analyses, we explored several study-level variables, such as gender, mean age, year of publication, and mean length of follow-up, which may account for the heterogeneity of mortality risks and possess potential confounding effects. Among them, only mean length of follow-up reached significance $(p<0.05)$, which was further included in Model 2 (Model 5). The results showed that studies with longer follow-up periods tended to have weaker associations between daily ST and mortality risks (see Table 1 ). The moderation effect of ST measurement was further examined in Model 5, indicating that the interaction effect remained similar $(p=0.01)$.

\section{Visual assessment of dose-response relationships}

The scatter plot of Model 1 illustrates the association of log-transformed mortality risk and doses of sitting time per day treated as a continuous variable (Fig. 2). The regression line and the upper and lower lines for 95\% CI showed that increased hazards of death from all causes became significant when total ST exceeded approximately $7.5 \mathrm{~h} /$ day.

The scatter plot of Model 3 (Fig. 3a) revealed that mortality risk significantly increased when daily ST exceeded $7 \mathrm{~h}$ /day in studies with subjective measurement. In contrast, the potential cut-off time duration for those with device-based assessment was close to $9 \mathrm{~h}$ (Fig. 3b).

\section{Assessment of publication bias}

No evidence of funnel plot asymmetry was observed (Additional file 4: Figure S1). There was no indication of publication bias with Egger's test, $p=0.46$ or with the "trim and fill" adjustment. The observed point estimate in log units was 0.11 (95\% CI 0.07-0.15), which is similar to the adjusted estimate after imputing two studies: 0.10 (95\% CI 0.06-0.14).

\section{Discussion}

The present meta-regression analyses based on pooled data for more than 1 million participants from 19 well-designed

Table 1 Dose-response relationships of sedentary time with all-cause mortality assessed using random-effects meta-regression models

\begin{tabular}{|c|c|c|c|c|}
\hline Models & Number of ES & Coefficients (SE) & $t$ & $p$ value \\
\hline Model 1 & 57 & & & \\
\hline Sedentary time & & $0.03(0.01)$ & 4.92 & $<0.001$ \\
\hline Model 2 & 57 & & & \\
\hline Sedentary time & & $0.03(0.01)$ & 5.08 & $<0.001$ \\
\hline Measurement (device-based $=1$ ) & & $0.11(0.05)$ & 2.39 & 0.03 \\
\hline Model 3 (subjective measures) & 36 & & & \\
\hline Sedentary time & & $0.03(0.01)$ & 5.09 & $<0.001$ \\
\hline Model 4 (device-based measures) & 21 & & & \\
\hline Sedentary time & & $0.09(0.03)$ & 3.04 & 0.001 \\
\hline Model 5 (sensitivity analysis) & 57 & & & \\
\hline Sedentary time & & $0.03(0.005)$ & 6.21 & $<0.001$ \\
\hline Measurement (device-based $=1$ ) & & $0.09(0.04)$ & 2.19 & 0.03 \\
\hline Follow-up (5-9 vs. < 5 years) & & $-0.09(0.04)$ & -2.16 & 0.04 \\
\hline Follow-up (10+ vs. < 5 years) & & $-0.16(0.04)$ & -3.88 & $<0.001$ \\
\hline
\end{tabular}

ES effect size, SE standard error

To test for moderation effects, the interaction term (sedentary time $\times$ measurement [device-based vs. subjective measure]) was further added into Model 2 $(p=0.02)$ and Model $5(p=0.01)$

$t$ Knapp-Hartung method 


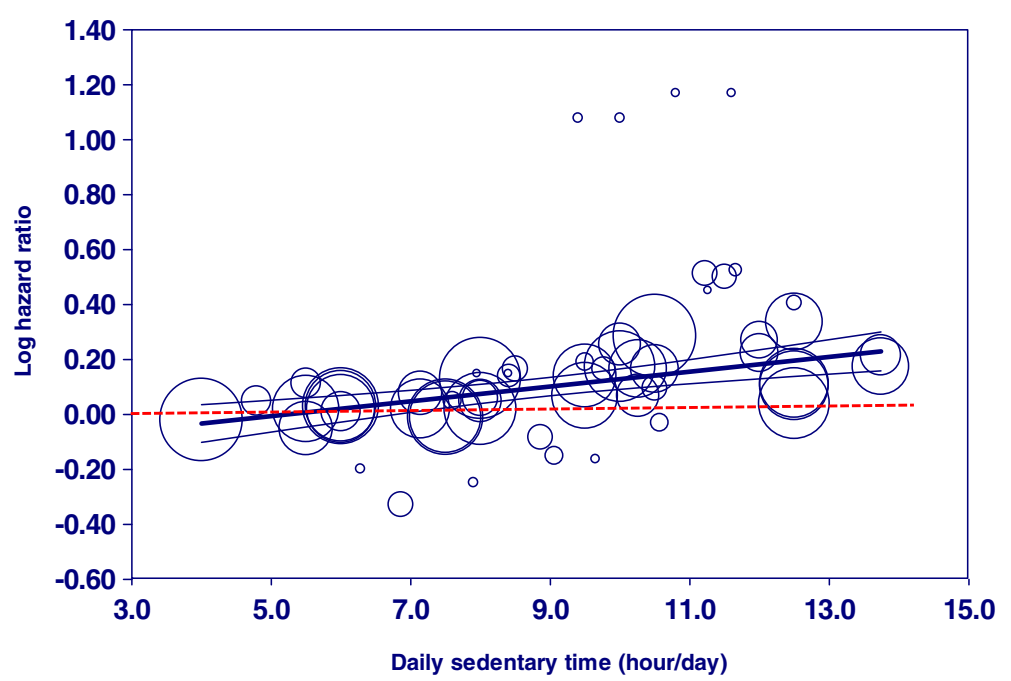

Fig. 2 Meta-regression of all-cause mortality risk on daily sedentary time (including all studies). Each study is represented by a circle. The size of each circle is proportional to that study's weight. The center line and the upper and lower lines show the predicted values and their $95 \%$ confidence intervals. Note: The meta-regression model was adjusted for follow-up time of each study

prospective cohort studies revealed a significant log-linear association between daily ST and all-cause mortality (i.e., HR) in adults. Overall, more time spent in sedentary behaviors is prospectively associated with increased mortality risks. Interestingly, there is a role for the method of measurement of ST in modulating the effect of daily ST on subsequent mortality risks across studies. The cut-off duration of daily ST in studies with subjective measures was more than $7 \mathrm{~h}$. In contrast, the cut-off point for those with device-based measures was close to $9 \mathrm{~h}$. These findings were supported by the meta-regression analyses adjusting for follow-up periods of each study. All of the pooled estimates were derived from large-scale prospective cohort studies with high-quality design and adjusted for multiple underlying confounding factors, including MVPA. Collectively, they provide additional evidence for ST recommendation.
The current meta-analysis study based on 19 prospective cohort studies (12 self-reported vs. 7 device-based) found that the optimal amount of daily ST in adults should be less than $7.5 \mathrm{~h}$. This is close to a previous meta-analysis of cohort studies (5 self-reported vs. 1 device-based) [8], suggesting a cut-off time interval of $7 \mathrm{~h}$, and is somewhat higher than the cut-off of $5 \mathrm{~h}$ (the midpoint of the category 4-6 h/day) revealed by another recent meta-analysis of cohort studies (13 studies all based on self-report measures) [9]. This inconsistency may be partly due to variation in the studies included in each review, which comprised studies based on different measures of ST.

This review using meta-regression found that the measurement method may moderate the associations between ST and all-cause mortality across studies. The magnitude of associations was stronger in studies using a

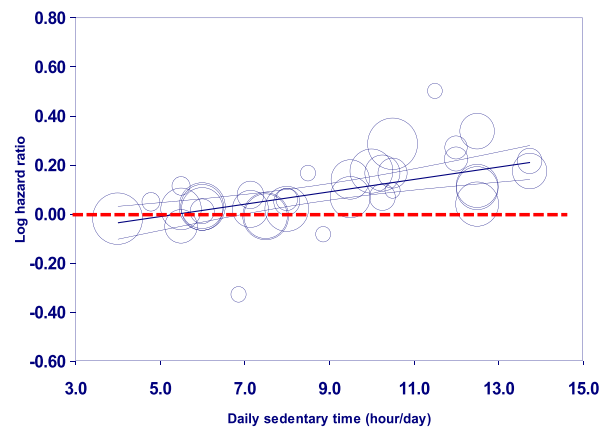

b

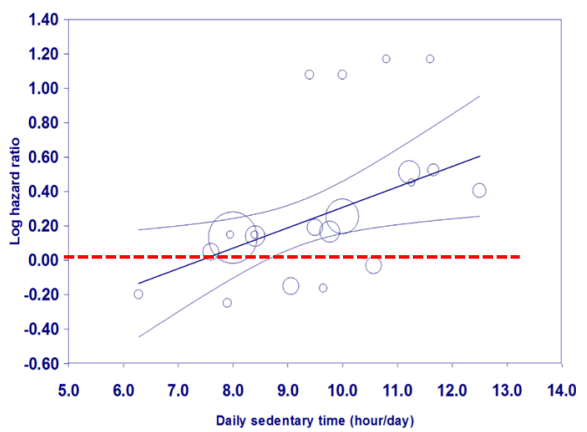

Fig. 3 Meta-regression of all-cause mortality risk on daily sedentary time based on studies with different measures (a subjective vs. b device-based). Each study is represented by a circle. The size of each circle is proportional to that study's weight. The center line and the upper and lower lines show the predicted values and their 95\% confidence intervals. Note: The meta-regression models were adjusted for follow-up time of each study 
device-based devices than in those with self-report ST. Previous evidence suggests that questionnaires involving multiple contexts for assessing daily ST are more likely to overestimate total ST in comparison with accelerometerbased devices [53]. In contrast, daily ST assessed using a single item such as the International Physical Activity Questionnaire (IPAQ) leads to an underestimate of total daily ST ranging from 2 to $3.5 \mathrm{~h}[54,55]$. In the present review, 10 out of the 12 studies based on self-report ST employed only one or two items to assess daily ST. It is possible that a questionnaire with one or two items is not able to capture the variability of sedentary behaviors that occurs in different contexts. This may partially explain why the cut-off in studies with subjective measurement was $7 \mathrm{~h} /$ day in comparison with $9 \mathrm{~h} /$ day in those with device-based assessment, and why the magnitude of relationships was greater in studies using device-based measures. Therefore, the appropriate cut-off duration for daily ST in adults may be around $9 \mathrm{~h}$, although this finding is based on a small number of studies with device-based measures. It is worth noting that the relationships of mortality risk (i.e., HR) with ST are log-linear. Participants spending more than $9 \mathrm{~h}$ /day had a significant increased risk of mortality $(\mathrm{HR}=1.22)$, with a rapid escalation from $10 \mathrm{~h} /$ day $(\mathrm{HR}=1.35), 12 \mathrm{~h} /$ day $(\mathrm{HR}=1.63)$, to $14 \mathrm{~h} /$ day $(\mathrm{HR}=1.96)$ (based on Model 1 in Table 1 , data not shown).

The moderating effect of type of measurement on the relationships of ST with mortality risks was further supported by the sensitivity analysis that took the length of follow-up into account. Studies with longer follow-up periods were more likely to have weaker associations between daily ST and mortality risks. This issue has not been documented in previous relevant meta-analyses $[8,9]$, and there is no clear explanation for the result. But it is possible that sedentary behaviors change over time, attenuating the associations between baseline estimates and all-cause mortality. Although the studies with a shortened period of follow-up may increase the possibility of reverse causality, several studies included in this review have demonstrated that similar results remained after excluding those dying in the first year $[15,40,47]$ or in the first 3 years [42].

There are several strengths in this meta-analysis. First, it is the first meta-regression based on 19 high-quality cohort studies that has examined the moderating effect of type of ST measurement on the dose-response relationships with mortality risk. Second, the large-scale pooled data for more than 1 million participants allowed the dose-response analyses to yield more precise effect estimates than previously obtained. Finally, mortality ascertainment was based on official death registry records, which is more likely to be accurate than other methods of assessment.
The main limitation of this meta-analysis is the small number of high-quality studies, especially those with device-based ST [8]. Furthermore, although the pooled estimates were based on large-scale prospective cohort studies with high-quality design and adjusted for multiple underlying confounding factors including moderate-tovigorous physical activity (MVPA), there remains the possibility of reverse causality or unmeasured confounding [8]. The mean age of participants in the studies analyzed ranged from 39.7 to 63.8 years old, which may limit the generalizability of the findings to the wider adult population. Additionally, the studies using device-based measures in the current review provide more accuracy of ST estimation, but they could not detect the difference between standing and sitting, which is a limitation of monitoring daily sedentary time. Finally, the current analyses were based on all-cause mortality as the outcome, and other thresholds for ST duration may be relevant to different outcomes, such as non-fatal illness or adiposity.

An international study involving 10 countries using accelerometry found that average sedentary time (ST) per day was $8.65 \mathrm{~h}$ among adults [1], which is close to the cut-off $(9 \mathrm{~h})$ of daily ST in adults observed in the current study. This means that nearly half of adults are at risk of increased mortality, and immediate action is needed to address the rise of sedentary lifestyle as a global trend. A previous meta-analysis demonstrated that MVPA potentially moderates the association of ST with mortality. Those who were active for about $60-75 \mathrm{~min}$ of MVPA every day did not have an increased risk of mortality even if they sat for more than $8 \mathrm{~h}$ per day [9]. Notably, those findings indicated distinct sittingmortality effects at different levels of MVPA, revealing that the cut-off of ST may be different among adults with different levels of MVPA. However, those metaanalyses were all based on studies using self-reported measures of ST, which should be further verified using studies with device-based ST, especially with a large sample size.

\section{Conclusions}

This meta-analysis suggests that there is a log-linear dose-response association between daily ST and allcause mortality in adults. The method of measurement could moderate the relationships of daily ST with subsequent mortality risks. This review suggests that it is appropriate to encourage adults to engage in less sedentary behaviors, with fewer than $9 \mathrm{~h}$ a day being relevant for all-cause mortality. There is a pressing need for more longitudinal studies involving device-based measures of ST and examining other thresholds for ST duration for all-cause mortality and other different outcomes such as non-fatal illness or adiposity. 


\section{Additional files}

Additional file 1: Table S1. Characteristics of studies included in the meta-regression. (DOCX $37 \mathrm{~kb}$ )

Additional file 2: Table S2. Quality assessment of systematic reviews by Kmet, Lee, and Cook rating. (DOCX 27 kb)

Additional file 3: Table S3. Goodness of fit for meta-regression models. (DOCX $22 \mathrm{~kb}$ )

Additional file 4: Figure S1. Funnel plot of standard error by log rate ratio. (PDF $7 \mathrm{~kb}$ )

\section{Abbreviations}

BMI: Body mass index; Cl: Confidence interval; HR: Hazard ratio; M: Mean; MVPA: Moderate to vigorous physical activity; OR: Odds ratio; PA: Physical activity; RR: Relative risk; SE: Standard error; ST: Sedentary time

\section{Funding}

This study was funded by the Taiwan Ministry of Science and Technology (MOST 105-2628-H-018-001-MY2). The funders had no role in the study design, data collection, data analysis and interpretation, or the content of the final manuscript.

\section{Availability of data and materials}

All the data supporting our findings are presented in Additional file 1: Table S1.

\section{Authors' contributions}

PK, AS, and LC conceived and designed the study. YL and MH acquired the data, checked data extractions, and conducted the assessment of study quality. PK obtained funding and carried out the statistical analysis. AS interpreted the data, advised on the structure of the manuscript, and revised the draft of the paper. PK and LC drafted the manuscript, and all authors critically revised the manuscript. All authors have read and approved the final manuscript. PK and $\mathrm{MH}$ had full access to all the data and take responsibility for the integrity of the data and the accuracy of the data analysis.

\section{Ethics approval and consent to participate}

Not applicable.

\section{Competing interests}

The authors declare that they have no competing interests.

\section{Publisher's Note}

Springer Nature remains neutral with regard to jurisdictional claims in published maps and institutional affiliations.

\section{Author details}

${ }^{1}$ Graduate Institute of Sports and Health, National Changhua University of Education, Changhua City, Taiwan. ${ }^{2}$ Department of Behavioural Science and Health, University College London, London, UK. ${ }^{3}$ Department of Health Promotion and Health Education, National Taiwan Normal University, Taipei, Taiwan. ${ }^{4}$ Department of Physical Education, National Taiwan Normal University, NO.162, He-ping East Road, Section 1, Taipei 106, Taiwan. ${ }^{5}$ Department of Exercise Health Science, National Taiwan University of Sport, No. 16, Section 1, Shuang-Shih Rd., Taichung 404, Taiwan.

Received: 26 January 2018 Accepted: 25 April 2018

Published online: 25 May 2018

\section{References}

1. van Dyck D, Cerin E, De Bourdeaudhuij I, Hinckson E, Reis RS, Davey R, Sarmiento OL, Mitas J, Troelsen J, MacFarlane D. International study of objectively-measured physical activity and sedentary time with body mass index and obesity: IPEN adult study. Int J Obesity. 2015;39(2):199-207.

2. de Rezende LF, Sá TH, Mielke Gl, Viscondi JYK, Rey-López JP, Garcia LMT. Allcause mortality attributable to sitting time: analysis of 54 countries worldwide. Am J Prev Med. 2016;51(2):253-63.
3. Biddle SJH, Bennie JA, Bauman AE, Chau JY, Dunstan D, Owen N, Stamatakis E, van Uffelen JGZ. Too much sitting and all-cause mortality: is there a causal link? BMC Public Health. 2016;16(1):635.

4. Young D, Hivert M-F, Alhassan S, Camhi S, Ferguson J, Katzmarzyk P, Lewis C, Owen N, Perry C, Siddique J, et al. Sedentary behavior and cardiovascular morbidity and mortality: a science advisory from the American Heart Association. Circulation. 2016;134:e262-79.

5. UK Department of Health. Physical activity guidelines for adults (19-64 years). London: Department of Health; 2011.

6. Australian Department of Health. Australia's Physical Activity and Sedentary Behaviour Guidelines for Adults (18-64 years). Canberra: Department of Health; 2014.

7. Australian National Preventive Health Agency. Obesity: Sedentary behaviours and health. Sydney: Australian National Preventive Health Agency; 2014.

8. Chau JY, Grunseit AC, Chey T, Stamatakis E, Brown WJ, Matthews CE, Bauman $A E$, van der Ploeg HP. Daily sitting time and all-cause mortality: a meta-analysis. PLoS One. 2013;8(11):e80000.

9. Ekelund U, Steene-Johannessen J, Brown WJ, Fagerland MW, Owen N, Powell KE, Bauman A, Lee IM. Does physical activity attenuate, or even eliminate, the detrimental association of sitting time with mortality? A harmonised meta-analysis of data from more than 1 million men and women. Lancet. 2016;388(10051):1302-10.

10. Kang M, Rowe DA. Issues and challenges in sedentary behavior measurement. Meas Phys Educ Exerc Sci. 2015;19(3):105-15.

11. Clark B, Sugiyama T, Healy G, Salmon J, Dunstan D, Owen N. Validity and reliability of measures of television viewing time and other nonoccupational sedentary behaviour of adults: a review. Obesity Review. 2009; 10(1):7-16.

12. Koolhaas CM, Dhana K, van Rooij FJ, Kocevska D, Hofman A, Franco OH Tiemeier $\mathrm{H}$. Sedentary time assessed by actigraphy and mortality: The Rotterdam Study. Prev Med. 2017:95:59-65.

13. Matthews CE, Keadle SK, Troiano RP, Kahle L, Koster A, Brychta R, Van Domelen D, Caserotti P, Chen KY, Harris TB. Accelerometer-measured doseresponse for physical activity, sedentary time, and mortality in US adults. Am J Clin Nutr. 2016;104(5):1424-32.

14. Edwards MK, Loprinzi PD. All-cause mortality risk as a function of sedentary behavior, moderate-to-vigorous physical activity and cardiorespiratory fitness. Phys Sportsmed. 2016;44(3):223-30.

15. Koster A, Caserotti P, Patel KV, Matthews CE, Berrigan D, Domelen DR, Brychta RJ, Chen KY, Harris TB. Association of sedentary time with mortality independent of moderate to vigorous physical activity. PLoS One. 2012;7:e37696.

16. Kmet LM, Lee RC, Cook LS: Standard quality assessment criteria for evaluating primary research papers from a variety of fields, vol. 22. Edmonton: Alberta Heritage Foundation for Medical Research; 2004.

17. Aune D, Chan DS, Lau R, Vieira R, Greenwood DC, Kampman E, Norat T. Dietary fibre, whole grains, and risk of colorectal cancer: systematic review and doseresponse meta-analysis of prospective studies. BMJ. 2011;343:d6617.

18. Grosso G, Micek A, Godos J, Pajak A, Sciacca S, Galvano F, Giovannucci El. Dietary flavonoid and lignan intake and mortality in prospective cohort studies: Systematic review and dose-response meta-analysis. Am J Epidemiol. 2017;185(12):1304-16.

19. Higgins J, Thompson SG. Quantifying heterogeneity in a meta-analysis. Stat Med. 2002;21(11):1539-58.

20. Burgers AMG, Biermasz NR, Schoones JW, Pereira AM, Renehan AG, Zwahlen M, Egger M, Dekkers OM. Meta-analysis and dose-response metaregression: circulating insulin-like growth factor I (IGF-I) and mortality. J Clin Endocrinol Metabol. 2011:96(9):2912-20.

21. Bagnardi V, Zambon A, Quatto P, Corrao G. Flexible meta-regression functions for modeling aggregate dose-response data, with an application to alcohol and mortality. Am J Epidemiol. 2004;159(11):1077-86.

22. Borenstein $M$, Hedges L, Higgins J, Rothstein H. Comprehensive MetaAnalysis Version 3. Englewood: Biostat; 2014

23. Knapp G, Hartung J. Improved tests for a random effects meta-regression with a single covariate. Stat Med. 2003;22(17):2693-710

24. Borenstein $M$, Hedges LV, Higgins J, Rothstein HR. Introduction to metaanalysis. Chichester: Wiley Online Library; 2009

25. Egger M, Smith GD, Schneider M, Minder C. Bias in meta-analysis detected by a simple, graphical test. BMJ. 1997;315(7109):629-34.

26. Duval S, Tweedie R. A nonparametric "trim and fill" method of accounting for publication bias in meta-analysis. J Am Stat Assoc. 2000;95(449):89-98. 
27. Moher D, Liberati A, Tetzlaff J, Altman DG, Group P. Preferred reporting items for systematic reviews and meta-analyses: The PRISMA statement. PLoS Med. 2009;6:e1000097.

28. Matthews CE, Moore SC, Sampson J, Blair A, Xiao Q, Keadle SK, Hollenbeck A, Park Y. Mortality benefits for replacing sitting time with different physical activities. Med Sci Sports Exerc. 2015;47(9):1833.

29. Dohrn M, Sjöström M, Kwak L, Oja P, Hagströmer M. Accelerometermeasured sedentary time and physical activity—a 15 year follow-up of mortality in a Swedish population-based cohort. J Sci Med Sport. 2017; https://doi.org/10/1016/j.jsams.2017.10.035

30. Diaz KM, Howard VJ, Hutto B, Colabianchi N, Vena JE, Safford MM, Blair SN, Hooker SP. Patterns of sedentary behavior and mortality in US middle-aged and older adults: a national cohort study. Ann Intern Med. 2017;167(7):465-75.

31. Schmid D, Ricci C, Leitzmann MF. Associations of objectively assessed physical activity and sedentary time with all-cause mortality in US adults: the NHANES study. PLoS One. 2015;10(3):e0119591.

32. Wang A, Qin F, Hedlin H, Desai M, Chlebowski R, Gomez S, Eaton CB, Johnson KC, Qi L, Wactawski-Wende J. Physical activity and sedentary behavior in relation to lung cancer incidence and mortality in older women: The Women's Health Initiative. Int J Cancer. 2016;139(10):2178-92.

33. Stamatakis E, Rogers K, Ding D, Berrigan D, Chau J, Hamer M, Bauman A. Allcause mortality effects of replacing sedentary time with physical activity and sleeping using an isotemporal substitution model: a prospective study of 201,129 mid-aged and older adults. Int J Behav Nutr Phys Act. 2015;12:121.

34. Katzmarzyk PT, Church TS, Craig CL, Bouchard C. Sitting time and mortality from all causes, cardiovascular disease, and cancer. Med Sci Sports Exerc. 2009:41:998-1005.

35. Krokstad S, Ding D, Grunseit AC, Sund ER, Holmen TL, Rangul V, Bauman A. Multiple lifestyle behaviours and mortality, findings from a large populationbased Norwegian cohort study — the HUNT Study. BMC Public Health. 2017; 17(1):58.

36. Schmid D, Ricci C, Baumeister SE, Leitzmann MF. Replacing sedentary time with physical activity in relation to mortality. Med Sci Sports Exerc. 2016; 48(7):1312-9.

37. Inoue M, Iso H, Yamamoto S, Kurahashi N, Sasazuki S, Tsugane S. Daily total physical activity level and premature death in men and women: results from a large-scale population-based cohort study in Japan (JPHC Study). Ann Epidemiol. 2008;18:522-30.

38. Matthews CE, Cohen SS, Fowke JH, Han X, Xiao Q, Buchowski MS, Hargreaves MK, Signorello LB, Blot WJ. Physical activity, sedentary behavior, and cause-specific mortality in black and white adults in the Southern Community Cohort Study. Am J Epidemiol. 2014;180(4):394-405.

39. Matthews CE, George S, Moore S, Bowles H, Blair A, Park Y, Troiano R, Hollenbeck A, Schatzkin A. Amount of time spent in sedentary behaviors and cause-specific mortality in US adults. Am J Clin Nutr. 2012;95:437-45.

40. van der Ploeg HP, Chey T, Korda RJ, Banks E, Bauman A. Sitting time and allcause mortality risk in 222,497 Australian adults. Arch Intern Med. 2012; 172(6):494-500.

41. Petersen CB, Bauman A, Grønbæk M, Helge JW, Thygesen LC, Tolstrup JS. Total sitting time and risk of myocardial infarction, coronary heart disease and all-cause mortality in a prospective cohort of Danish adults. Int J Behav Nutr Phys Act. 2014;11(1):13.

42. Grunseit AC, Chau JY, Rangul V, Holmen TL, Bauman A. Patterns of sitting and mortality in the Nord-Trøndelag health study (HUNT). Int J Behav Nutr Phys Act. 2017;14(1):8.

43. Kim Y, Wilkens LR, Park S-Y, Goodman MT, Monroe KR, Kolonel LN. Association between various sedentary behaviours and all-cause, cardiovascular disease and cancer mortality: the Multiethnic Cohort Study. Int J Epidemiol. 2013;42:1040-56.

44. Pulsford RM, Stamatakis E, Britton AR, Brunner EJ, Hillsdon M. Associations of sitting behaviours with all-cause mortality over a 16-year follow-up: the Whitehall II study. Int J Epidemiol. 2015;44(6):1909-16.

45. Seguin R, Buchner DM, Liu J, Allison M, Manini T, Wang C-Y, Manson JE, Messina CR, Patel MJ, Moreland L. Sedentary behavior and mortality in older women: the Women's Health Initiative. Am J Prev Med. 2014;46(2):122-35.

46. Hagger-Johnson G, Gow AJ, Burley V, Greenwood D, Cade JE. Sitting time, fidgeting, and all-cause mortality in the UK Women's Cohort Study. Am J Prev Med. 2016;50(2):154-60.
47. Chau JY, Grunseit A, Midthjell K, Holmen J, Holmen TL, Bauman AE, Ploeg HP. Sedentary behaviour and risk of mortality from all causes and cardiometabolic diseases in adults: evidence from the HUNT3 population cohort. Br J Sports Med. 2015;49:737-42.

48. Ding D, Rogers K, van der Ploeg H, Stamatakis E, Bauman AE. Traditional and emerging lifestyle risk behaviors and all-cause mortality in middle-aged and older adults: evidence from a large population-based Australian cohort. PLoS Med. 2015;12(12):e1001917.

49. Evenson KR, Herring AH, Wen F. Accelerometry-assessed latent class patterns of physical activity and sedentary behavior with mortality. Am J Prev Med. 2017:52(2):135-43.

50. Evenson KR, Wen F, Herring AH. Associations of accelerometry-assessed and self-reported physical activity and sedentary behavior with all-cause and cardiovascular mortality among US adults. Am J Epidemiol. 2016;184(9):621-32.

51. Lee PH. Examining non-linear associations between accelerometermeasured physical activity, sedentary behavior, and all-cause mortality using segmented Cox regression. Front Physiol. 2016;7:272.

52. Higgins J, Thompson SG, Deeks JJ, Altman DG. Measuring inconsistency in meta-analyses. BMJ. 2003;327(7414):557-60.

53. Busschaert C, De Bourdeaudhuij I, Van Holle V, Chastin SF, Cardon G, De Cocker K. Reliability and validity of three questionnaires measuring contextspecific sedentary behaviour and associated correlates in adolescents, adults and older adults. Int J Behav Nutr Phys Act. 2015;12(1):117.

54. Gupta N, Christiansen CS, Hanisch C, Bay H, Burr H, Holtermann A. Is questionnaire-based sitting time inaccurate and can it be improved? A cross-sectional investigation using accelerometer-based sitting time. BMJ Open. 2017;7(1):e013251.

55. Chastin S, Culhane B, Dall P. Comparison of self-reported measure of sitting time (IPAQ) with objective measurement (activPAL). Physiol Meas. 2014; 35(11):2319.

\section{Ready to submit your research? Choose BMC and benefit from:}

- fast, convenient online submission

- thorough peer review by experienced researchers in your field

- rapid publication on acceptance

- support for research data, including large and complex data types

- gold Open Access which fosters wider collaboration and increased citations

- maximum visibility for your research: over $100 \mathrm{M}$ website views per year

At BMC, research is always in progress.

Learn more biomedcentral.com/submissions 